\title{
ARTÍCULOS
}

\section{LA PARADOJA DE LA IMPOSIBILIDAD DEL CONOCIMIENTO EN EL}

MENÓN.

Carlos Fernando Ramírez González ${ }^{1}$

\section{RESUMEN}

La paradoja que aparecen en el diálogo del Menón inaugura un periodo de reflexión en la filosofía platónica. El análisis argumentativo permite ver cómo está conectados estos elementos nuevos: por un lado, se abandona el elenco como la forma prominente para hacer filosofía, junto con ello aparece una propuesta epistemológica que será determinante en el pensamiento de Platón y que en el diálogo (Menón) permite superar el "argumento erístico" con que Menón intenta suspender la disputa.

Los argumentos de este pasaje han sido analizados por muchos autores, lo novedoso de mi propuesta es que se hace desde una teoría que considera que la argumentación no es sólo la suma de los argumentos, sino que considera que existen elementos que van más allá de las premisas y la conclusión, que son determinantes en la resolución del diálogo.

\section{ABSTRAC}

The paradox that appears in the Menon's dialogue opens a period of reflection in Platonic philosophy. The argumentative analysis allows us to see how these new

1 Profesor Investigador del Centro Universitario de Ciencias Sociales y Humanidades de la Universidad de Guadalajara, México.

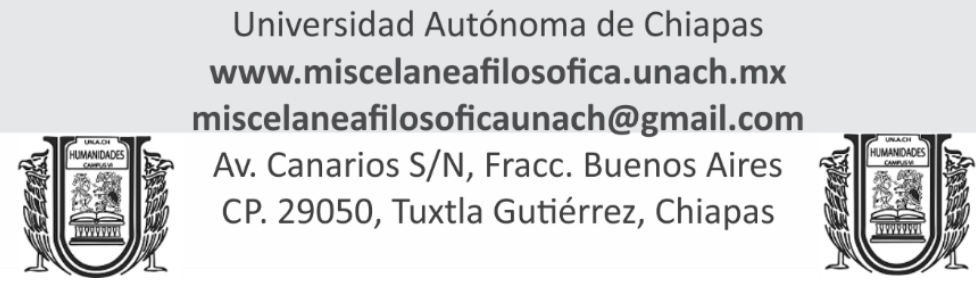


| Cuatrimestral Facultad de Humanidades Campus VI Reserva de Derechos al Uso Exclusivo No.: 04-2018-060814012200-203| ISSN: 2594-1755

Año III | Número 7 | Septiembre- Diciembre 2019

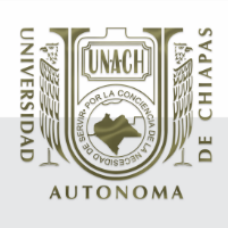

\section{ARTÍCULOS}

Argumento único no mixto.

1. La filosofía no es una ciencia

porque

1.1 No tiene un objeto de estudio bien delimitado, $\mathbf{y}$

$\left(1.1^{\prime}\right)$ (Toda ciencia tiene un objeto bien delimitado).

Argumento múltiple.

1. No es posible que me hayas visto ayer en Sanborns de Plaza Patria de Guadalajara. porque

1.1 en Plaza Patria no hay Sanborns o

porque

1.2 todo el día de ayer estuve en la Ciudad de México ${ }^{13}$.

Argumento coordinado.

1. No quiero comer carne,

porque

1.1 a ya es tarde $\mathbf{y}$

$1.1 \mathrm{~b}$ me puede caer pesada.

Argumento subordinado

1. El alma es inmortal

porque

1.1 el alma es indivisible

porque

1.1.1 lo indivisible nunca muere

13 Aquí 1.1 y 1.2 apoyan de manera independiente al punto de vista 1, de tal forma que una de ellas es suficiente para sostenerlo. 
| Cuatrimestral Facultad de Humanidades Campus VI Reserva de Derechos al Uso Exclusivo No.: 04-2018-060814012200-203| ISSN: 2594-1755

Año III | Número 7 | Septiembre- Diciembre 2019

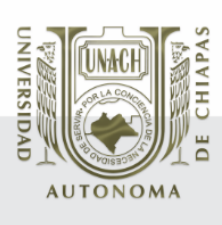

\section{ARTÍCULOS}

Página web consultada

Perseus Hopper. The Perseus Digital Library.

http://www.perseus.tufts.edu/hopper/collection?collection=Perseus:collec tion:Greco-Roman, última consulta mayo del 2019. 